\title{
(IM) POSSIBILIDADE DA RELATIVIZAÇÃO DO PRINCÍPIO DA RECIPROCIDADE NA PRESTAÇÃO DE ALIMENTOS- DIREITO DE FAMÍLIA
}

\author{
Eduardo Borovicz dos Santos ${ }^{1}$
}

RESUMO: Abordar a possibilidade da relativização do princípio da reciprocidade na prestação de alimentos, diante da ausência de previsão legislativa que autorize tal prática. A necessidade da aplicação desse princípio, nas relações familiares, faz com que o aplicador do direito se valha da analogia para solucionar questões que envolvem a cessação da obrigação de prestar alimentos. Alguns doutrinadores defendem que, mesmo com o fim da ruptura do afeto e do convívio familiar, a responsabilidade de alimentos entre ascendente e descente permanece, pois o princípio da reciprocidade e da afetividade continuaria vigente entre os familiares. $\mathrm{Na}$ hipótese de necessidade de alimentos de um deles, o outro possui o direito de pleitear o pedido de alimentos.

Palavras-chaves: Direito. Reciprocidade. Prestação de alimentos.

\section{INTRODUÇÃO}

Impende destacar que se objetiva tratar no presente trabalho sobre as lacunas da legislação civilista no que tange à cessação da obrigação alimentar entre pais e filhos.

Os artigos 557 e I.8I4 do Código Civil (BRASIL, 2003), que tratam respectivamente da revogação das doações e das exclusões da sucessão, são usados atualmente para fundamentar a relativização da prestação de alimentos entre pais e filhos. Observa-se, portanto, que existe omissão na legislação no que tange à relativização do princípio da reciprocidade na obrigação de alimentar entre pais e filhos.

A Constituição Federal de 1988 preceitua, em seu artigo 229, que é dever do filho zelar pelos cuidados dos pais na velhice ou em momento de carência, sendo recíproco esse dever, se estendendo a obrigação quanto ao dever do pai sobre os filhos, devendo prestar a estes toda subsistência necessária (ROSENVALD, 2010).

\footnotetext{
' Pós- graduado em Direito de Família e Sucessões pela Damásio de Jesus (2019), Pós- graduado em Direito Contratual, Processo civil, Empresarial e MBA em Advocacia Cível (Polis Civitas) 2020. Graduação em Direito pelo Centro Universitário Univel. E-mail: adv.eduardo.jus@gmail.com
} 
Existem, contudo, situações em que os genitores faltam com o dever legal de cuidado para com a prole e mesmo assim futuramente invocam contra ela o princípio da reciprocidade ao demandarem pedido de alimentos.

Com base na doutrina e na jurisprudência, em tais casos se deve relativizar o princípio da reciprocidade. De acordo com Dias (20II), não se deve prosperar o fundamento dos genitores que requerem pedido de alimentos contra seu descente, uma vez que faltaram contra ele no passado com a obrigação que era de sua correspondência.

O princípio da reciprocidade se trata de uma via de mão dupla, pois apenas se poderá argui-lo, uma vez que a parte que está em vantagem econômica proveu à parte necessitada a subsistência que essa necessitava, sendo essa de pai para filho ou vice-versa (DIAS, 20II).

Com o presente trabalho pretende-se analisar as possibilidades de relativização do princípio da reciprocidade na obrigação alimentar, uma vez que os magistrados tem se utilizado da analogia para tanto, tendo em vista a omissão na legislação.

\section{O DIREITO DE ALIMENTOS NO DIREITO CIVIL BRASILEIRO E A LEGITIMIDADE DO CREDOR}

Sabe-se que o ser humano possui diversas naturezas que o acompanham desde o nascimento até a morte. Assim, aquele que fosse responsável por outrem deveria garantir que as necessidades desse fossem satisfeitas.

Por Del Vecchio (2013) surge um senso de justiça, por força de um princípio natural, haveria a imposição aos geradores de proporcionar aos gerados seu desenvolvimento e garantir-lhes não apenas a subsistência. Desde os primeiros conceitos de Estado, esse era responsável pela promoção da vida e da dignidade da pessoa humana, porém, com a dificuldade que havia de se cumprir com esse dever Estatal, houve a inserção nos ordenamentos jurídicos da solidariedade familiar como princípio, transferindo a responsabilidade do Estado para os familiares.

O Direito de alimentos no Direito Brasileiro possui uma finalidade mais ampla que o próprio sentido da palavra traz, pois além da alimentação, deve atender as necessidades básicas de quem os solicita, como vestuário, lazer, assistência médica e estudos.

Nos dizeres de Silvio Rodrigues (2004): 


\begin{abstract}
Alimentos, em direito, denomina-se a prestação fornecida a uma pessoa, em dinheiro ou em espécie, para que possa atender às necessidades da vida. A palavra alimentos tem conotação muito mais ampla do que na linguagem vulgar, em que significa o necessário para o sustento. Aqui trata-se não só do sustento, como também de vestuário, habitação, assistência médica, em caso de doença, enfim de todo o necessário para atender às necessidades da vida; e, em se tratando de criança, abrange o que for preciso para sua instrução (RODRIGUES, 2004, s/p).
\end{abstract}

Dias (2014) afirma que não são somente os ascendentes, descendentes e parentes de até segundo grau (irmãos) que devem assumir a obrigação alimentar. Consoante posicionamento da mestra, na falta deles, a obrigação passará aos tios, após, aos sobrinhos, e, finalmente, aos primos solidariamente.

Desse modo, em um sentido mais vasto, os alimentos devem atender a todas as necessidades vitais do necessitado, tendo como objetivo a manutenção de sua dignidade.

\title{
2.I MODALIDADES DE ALIMENTOS
}

Os alimentos englobam tudo aquilo que a pessoa necessita para viver com dignidade. O conceito de alimentos levou a doutrina a distingui-los em naturais e civis.

Ensina Cahali (20II) que,

quando se pretende identificar como alimentos aquilo que é estritamente necessário para a mantença da vida de uma pessoa, compreendendo tão somente a alimentação, a cura, o vestuário, a habitação, nos limites assim do necessarium vitae, diz-se que são alimentos naturais; todavia, se abrangentes de outras necessidades, intelectuais e morais, inclusive recreação do beneficiário, compreendendo assim o necessarium personae e fixados segundo a qualidade do alimentando e os deveres da pessoa obrigada, diz-se que são alimentos civis. ( CAHALI, 2011, s/p)

Os alimentos naturais são os indispensáveis para garantir a subsistência e englobam alimentação, vestuário, habitação, saúde, educação e etc (DIAS, 20II).

Esses alimentos eram deferidos aos companheiros e consortes, sendo apenas o indispensável à sobrevivência. Aquele que culposamente dá origem à situação de necessidade faz jus a prestação alimentar. Não se deve deixar de lado, porém, às necessidades educacionais e um mínimo razoável para o lazer e para atender às necessidades intelectuais (DIAS, 20II).

Os civis são os que se destinam a manter a qualidade de vida do alimentado, para que haja compatibilidade entre os modos de vida do credor e do alimentante. São os 
alimentos destinados aos filhos, de modo a conceder a eles a mesma condição de vida de seus pais (DIAS, 2011).

Roborando o assunto, segundo Venosa (2003):

Este artigo introduz em nosso direito, no $\S_{2}{ }^{\circ}$, ao lado dos alimentos necessários, o conceito de alimentos indispensáveis, devidos mesmo diante de culpa do credor, que permanece com o direito de ser alimentado. De grande valia é essa regra, porque, ao mesmo tempo em que atende ao princípio da solidariedade nas relações de parentesco, casamento e união estável, não deixa de reconhecer que em caso de culpa devem ser atendidas somente as necessidades básicas do alimentário, com a prestação do que é indispensável à sua subsistência. (VENOSA, 2003, p.377)

Diante das duas modalidades de alimentos analisadas, pode-se concluir que os naturais são os indispensáveis à vida, percebe-se fortemente a influência do princípio da dignidade da pessoa humana, uma vez que asseguram o mínimo para subsistência do credor. Para os civis que asseguram a qualidade de vida do alimentando, a percepção é quanto ao princípio da reciprocidade, garantindo assim as mesmas condições de vida que o prestador de alimentos.

\subsection{Requisitos para concessão dos alimentos}

Para a concessão dos alimentos, na obrigação alimentar são obedecidos a certos requisitos, são eles a existência de um vínculo de parentes, a necessidade do reclamante, a proporcionalidade e a possibilidade da pessoa obrigada.

A necessidade se baseia no fato de o indivíduo passar por necessidades e não possuir condições de arcar com a própria subsistência, por não possuir recursos próprios e estar impossibilitado de obtê-los pelo seu trabalho por estar doente, desempregado, inválido ou com idade avançada (DIAS, 20II).

Independente da razão que levou o indivíduo a necessidade dos alimentos, o mesmo não pode ficar à mercê da sorte para sobreviver. Nesse viés é o respaldo a dignidade da pessoa humana, haja vista da necessidade do indivíduo possuir um mínimo possível para sua subsistência e em razão dessa necessidade, poderá com base na solidariedade familiar, buscar amparo perante a família e parentes mais próximos (DIAS, 20II).

Preceitua Rosenvald (2010) que, por serem os alimentos essenciais à existência de qualquer indivíduo, "é de se concluir que a sua natureza é de direito da personalidade, pois 
se destinam a assegurar a integridade física, psíquica e intelectual de uma pessoa humana" (ROSENVALD, 2010, p. 669).

Já a proporcionalidade ampara o pedido de alimentos, pois esses não visam ao enriquecimento do alimentando e, assim, não há motivos para se exigir do devedor além das necessidades do credor (GONÇALVES, 2014).

Mesmo que o credor possua melhores condições financeiras que o devedor, ele não deve exigir além das suas possibilidades, de modo que afete a sua subsistência e de sua família. Desse modo, se deve levar em consideração as necessidades do devedor e o poder econômico do credor, de forma que a proporcionalidade seja a conciliação entre a necessidade e a possibilidade do alimentante e do alimentado (GONÇALVES, 2014).

Já a possibilidade complementa a necessidade, formando o binômio necessidade/possibilidade. O alimentante deverá cumprir com a obrigação alimentar fornecendo a verba alimentícia sem que venha a faltar para o seu sustento.

Não seria justo que alguém que sobrevive com o indispensável venha a prestar alimentos e se sujeite a ficar em condições precárias em razão dos grandes sacrifícios que venha a ter que passar para arcar com a verba alimentícia, sendo por isso que o alimentante deve arcar com o que cabe em suas possibilidades, dentro de seus limites.

Nesse sentido, assevera Carvalho (2009) que

O ideal é o alimentante possuir condições de satisfazer as necessidades do alimentado [...]. Não raras vezes, o pai percebe apenas o salário mínimo ou pouco mais e possui diversos filhos, exigindo sensibilidade do magistrado ao fixar os alimentos sem comprometer a própria sobrevivência do devedor e possibilitar o mínimo necessário para a subsistência do credor [...]. (CARVALHO, 2009, p.403).

Caso o alimentante não possa arcar na íntegra com as necessidades de seu credor alimentício, outro deve ser chamado solidariamente para completar a verba alimentícia, havendo assim solidariedade entre os devedores na satisfação da obrigação (GONÇALVES, 2014).

Os pressupostos da obrigação alimentar estão dispostos no art. I.694, § Io do Código Civil, o qual expõe que "os alimentos devem ser fixados na proporção das necessidades do reclamante e dos recursos da pessoa obrigada" (BRASIL, 2002, s/p). 
Assim, tem-se como pressupostos a existência de um vínculo de parentesco, estabelecido no caput do artigo supramencionado, a necessidade do reclamante, a possibilidade do reclamado e a proporcionalidade (GONÇALVES, 20I4).

A possibilidade de prestar alimentos daquele de quem se reclama, ou seja, do alimentante, é também uma situação que deve ser analisada quando da fixação da pensão alimentar, pois de acordo com a possibilidade do alimentante é que será fixada a quantia que deve ser dispensada em favor do alimentando (GONÇALVES, 2014).

A reciprocidade encontra respaldo no artigo I.696 do Código Civil sendo recíproca a obrigação alimentar. Dessa forma, aquele que prestar alimentos pode vir a pedi-los no futuro. Nessa situação os polos ativo e passivo serão invertidos de acordo com as condições econômicas financeiras dos indivíduos envolvidos na relação jurídica.

Assim, defende Quaranta (2013), que o princípio da reciprocidade e da solidariedade familiar na obrigação de prestar alimentos é uma via de mão dupla. Ou seja, aquele que se encontrar no polo passivo da pretensão alimentar poderá, futuramente, se tornar polo ativo e vice-versa.

Pode- se concluir, portanto, que junto à necessidade do alimentando vem o pressuposto do vínculo familiar entre o credor de alimentos e o devedor, sendo que a obrigação alimentar recai a princípio sobre os parentes de grau mais próximo, na falta dos ascendentes, caberá aos descendentes e na falta desses, caberá aos irmãos.

\subsection{Princípios que regem o direito de família e que reforçam o dever de alimentos}

A origem da obrigação dos alimentos está ligada à sua natureza jurídica, da qual deriva o poder familiar dos pais de sustentar os filhos.

A Constituição Federal de 1988 reconhece o dever de sustento dos genitores com relação à prole, o qual consiste em ajudar, criar e educar os filhos, fornecendo o mínimo para que eles venham a ter condições de se desenvolverem para a vida em sociedade (DINIZ, 2007).

Também é reconhecido o dever dos filhos maiores auxiliar e amparar os pais na velhice, na carência ou em casos de doença. Essa troca de obrigações e amparos trata-se de 
uma prestação alimentar, que encontra repouso na solidariedade familiar, entre os parentes em linha reta e se estende aos demais (DINIZ, 2007).

Enquanto a família vive sob o mesmo teto, ou seja, coabita, os alimentos são in natura. Com a separação dos familiares, a obrigação alimentar converte-se em obrigação in pecúnia, à qual se atribuirá valor monetário a ser pago ao membro da família que necessita de amparo (DINIZ, 2007).

Nesse diapasão, se faz oportuno traçar breves comentários sobre os princípios que regem as relações familiares e que podem ser invocados para justificar o dever de alimentos na relação familiar.

\section{I Princípio da solidariedade}

Derivado dos vínculos afetivos, o princípio da solidariedade é regido pelo dever que os familiares têm um para com o outro. Esse princípio possui caráter constitucional, pois é respaldado pelo artigo 229 da Constituição Federal (DIAS, 20II).

Consoante com o artigo I.694 do Código Civil, os integrantes da família são em regra credores e devedores de alimentos uns dos outros de forma recíproca, e a imposição dessa obrigação alimentar entre parentes representa a solidariedade familiar de forma concretizada (DIAS, 20II).

A respeito de tal tema, Rosenvald (2010) defende a ótica do princípio da solidariedade e afirma que

Cristalina é a observação de que não se vislumbra uma vida digna num indivíduo desprovido do mínimo essencial para se alimentar ou, que, não se chegará a uma sociedade bem estruturada e justa sem que se exerça o princípio da solidariedade entre os seres. Desta forma, o legislador, em nome do Estado, estabeleceu que aquele que em necessidade se encontrar, poderá pedir prestações com caráter de alimentos em face dos que ao seu redor se encontrem, em busca de sua subsistência (ROSENVALD, 2010, s/p).

Nesse mesmo sentido, Quaranta e Oliveira (2013) defendem que

Nesse contexto, de parentes ajudarem uns aos outros, que se encontra o caráter de solidariedade e de reciprocidade da obrigação alimentar. Isso porque tal obrigação baseia-se também, como dito alhures, no princípio da solidariedade entre os parentes, onde aquele que de qualquer forma contribuiu para o sustento de seu consanguíneo merece ser amparado por este caso necessite de alimentos futuramente (QUARANTA; OLIVEIRA, $2013 \mathrm{~s} / \mathrm{p}$ ). 
Ainda de acordo com Quaranta e Oliveira (2013), seria injusto "que o ascendente, quanto atingisse uma idade avançada e não tivesse condições de prover o próprio sustento, não pudesse contar com o auxílio material dos descendentes" (QUARANTA; OLIVEIRA, 2013, s/p).

O princípio da solidariedade se baseia na ideia do laço familiar como pressuposto de obrigação, sendo a consanguinidade meio para execução e exercício de um direito. Esse princípio se remete ao amor, ao carinho, ao afeto, respeito e reciprocidade incondicionais, sendo estes fatores que deveriam nortear a família independente de normas que regulem o círculo e as relações familiares (GONÇALVES, 2014).

O princípio da solidariedade, portanto, se baseia nos vínculos afetivos que um familiar tem pelo outro, recaindo sobre o parente mais próximo a responsabilidade de prestar alimentos quando um ente querido estiver em necessidade, não a podendo suprir sozinho, vindo assim a ser chamado solidariamente para prover alimentos.

\subsection{Princípio da proteção ao idoso}

A Lei n. 10.74I/2003 do Estatuto do Idoso (BRASIL, 2003) regula os alimentos devidos ao idoso de forma diferenciada e prescreve no artigo i2 que a solidariedade da obrigação alimentar devida ao idoso é optativa desse.

Assim sendo, quando os alimentos ao idoso possuírem caráter de urgência, se permite a escolha de um dentre os diversos devedores de alimentos (um filho, dos vários) para reclamar integralmente a pretensão alimentar (MADALENO, 2013).

Nesse caso, a solidariedade é excepcional e é imposta por força do artigo I2 do Estatuto do Idoso, o qual vincula como devedor qualquer dos parentes. Trata-se de uma mera faculdade que o credor (idoso) possui, o qual pode pedir os alimentos de qualquer dos devedores solidários, ou se preferir, pode dirigir seu pedido a todos solidariamente.

O idoso tem a faculdade de escolher mais de um dos diversos devedores, ou buscar aquele que simplesmente possui mais condições e que lhe dê maiores garantias de adimplemento do pagamento desses alimentos. Caso o devedor escolhido não possua condições de atender as necessidades integrais do idoso, pagará a sua parte que lhe 
corresponde e o credor irá acionar os outros devedores solidários para que atendam à integralidade de suas necessidades materiais (GONÇALVES, 2014).

Ao prever a situação acima exposta, o propósito do legislador foi de criar uma exceção da norma geral da divisibilidade alimentar ao configurar como solidário os alimentos da pessoa idosa. Como observa Pereira (1997), os alimentos, baseados na solidariedade, são fruto da concepção atual da entidade familiar, que tem em seus integrantes o foco das atenções. Segundo esse autor:

\begin{abstract}
A solidariedade, inerente à família - principalmente a nuclear e a binuclear, nas quais as pessoas são valorizadas por ser a atual família núcleo de companheirismo -, é o elemento propulsor da jurisdicização do amparo recíproco entre os membros da família. Os alimentos constituem um exemplo desta concepção solidarista, da qual também é elucidação a diretriz principiológica adotada pelos Estatutos da Criança e do Adolescente e do Idoso, que objetivam amparar aqueles que se encontram em situação peculiar de fragilidade, seja pela falta de discernimento e maturidade, seja pela velhice (PEREIRA, 1997, p.3).
\end{abstract}

Como visto, o princípio da proteção ao idoso se entrelaça perfeitamente com o princípio da solidariedade, uma vez que a pessoa idosa pleiteia o pedido de alimentos ao devedor solidário e, por ser uma obrigação alimentar com caráter de urgência diante da idade avançada de quem os solicita, ele pode escolher um único prestador de alimentos dentre os vários que pode possuir, sendo uma faculdade do idoso solicitar de um ou de vários solidariamente.

\title{
3.3 Princípio da dignidade da pessoa humana
}

Expressamente disposto no artigo Ioo, III da Constituição Federal, o princípio da dignidade da pessoa humana, macro princípio ou superprincípio, é considerado o mais universal de todos, pois não existe ser humano sem dignidade (MADADENO, 2013). Esse implica na valorização do indivíduo dentro das relações familiares, valorizando de maneira definitiva a pessoa humana. Esse princípio é norteador para a fixação dos alimentos, pois eles são fixados de acordo com as necessidades de quem os pleiteia e de acordo com as possibilidades de quem os cede (MADADENO, 2013).

O direito ao recebimento de alimentos possui como fundamento a dignidade da pessoa humana, pois esse princípio tem como objetivo preservar a vida humana, garantindo o mínimo para sua subsistência, sendo assim segurado por lei (DIAS, 20II). 
De acordo com Dias (201I)

A dignidade da pessoa humana encontra na família o solo apropriado para florescer. A ordem constitucional dá-lhe especial proteção independentemente de sua origem. A multiplicação das entidades familiares preserva e desenvolve as qualidades mis relevantes entre os familiares - o afeto, a solidariedade, a união, o respeito, a confiança, o amor, o projeto de vida comum-, permitindo o pleno desenvolvimento pessoal e social de cada participe com base em ideais pluralistas, solidaristas, democráticos e humanistas. (DIAS, 2oli, p.63).

Assim, a dignidade da pessoa humana, sendo uma qualidade intrínseca e indissociável de todo e qualquer ser humano deve ser preservado e garantido no direito de família, sendo que em termos práticos, se traduz no propósito de que todas as famílias e seus indivíduos tenham acesso a educação, alimentação, moradia e um crescimento próspero e saudável.

\subsection{Princípio da afetividade}

Como um dos principais princípios norteadores do Direito de Família, ele não busca definir o amor. A afetividade possui muitos aspectos e possui uma força propulsora em todas as relações de vida. A comunidade familiar é formada pelo liame socioafetivo que os vincula, de modo que não aniquilem suas individualidades.

De acordo com Calderón (2013),

O princípio da afetividade possui uma dupla face cuja compreensão auxilia na exata percepção do seu sentido. A primeira delas é a face de dever jurídico, voltada para as pessoas que possuam algum vínculo de parentalidade ou de conjugalidade II (aqui incluídas não só as relações matrimoniais, mas todas as uniões estáveis de alguma forma reconhecidas pelo sistema). Essa face do princípio vincula tais pessoas a condutas recíprocas representativas da afetividade inerente a tal relação. A segunda faceta do princípio é a face geradora de vínculo familiar, voltada para as pessoas que ainda não possuam um vínculo reconhecido pelo sistema (seja de parentalidade, seja de conjugalidade), pela qual a incidência do princípio da afetividade consubstanciará um vínculo familiar entre os envolvidos. Nessa particularidade resta abarcada a noção da posse de estado, ou seja, a presença de um dado conjunto fático fará incidir o princípio da afetividade de modo a configurar, a partir de então, um vínculo familiar decorrente daquela relação. (CALDERÓN, 2013, s/p)

Segundo Dias (20II)

De forma cômoda, o Judiciário busca subterfúgios no campo do Direito das Obrigações, identificando como uma sociedade de fato o que nada mais é do que uma sociedade de afeto. A exclusão de tais relacionamentos da órbita do Direito de Família acaba impedindo a concessão dos direitos que defluem das relações 
familiares, tais como: meação, herança, usufruto, habitação, alimentos, benefícios previdenciários, entre tantos outros. (DIAS, 2011, p.87)

O afeto não é fruto da biologia, deriva da convivência familiar e não do sangue. Tendo em vista que a família se transforma na medida em que se acentuam as relações de sentimentos entre seus membros, surgiu a necessidade do estado de tutelá-lo, e na esteira dessa evolução o Direito das Famílias instalou uma nova ordem jurídica para a família, atribuindo valor jurídico ao afeto.

Nessa órbita, Dias (20II) diz que

\begin{abstract}
A posse de estado de filho nada mais é do que o reconhecimento jurídico do afeto, com o claro objetivo de garantir a felicidade, como um direito a ser alcançado. $\mathrm{O}$ afeto não é somente um laço que envolve os integrantes de uma família. Igualmente tem um viés externo, entre as famílias, pondo humanidade em cada família, compondo, no dizer de Sérgio Resende de Barros, a família humana universal, cujo lar é a aldeia global, cuja base é o globo terrestre, mas cuja origem sempre será, como sempre foi, a família. (DIAS, 20II, p.7I).
\end{abstract}

Conclui-se que o princípio da afetividade é um dos princípios de base do Direito de Família, pois não se pode excluir a afetividade dos vínculos existentes entre os membros de uma família, sendo que a partir dela surgirá a obrigação familiar entre os indivíduos, ou ainda, na ausência dela, se eximirá de prestar alimentos.

\title{
4 A OBRIGAÇÃO DE ALIMENTAR ENTRE PAIS E FILHOS E A RELATIVIZAÇÃO DO PRINCÍPIO DA RECIPROCIDADE
}

A obrigação alimentar é recíproca entre cônjuges, companheiros e parentes para que eles possam viver de modo compatível com a sua condição social, inclusive para atender às necessidades de sua educação.

Essa reciprocidade existe de acordo com o artigo r.694 e 1.696 do Código Civil, pois quem presta alimentos também tem direito de recebê-los se vier a necessitar deles, o que acarreta em inversão da posição dos sujeitos da relação obrigacional alimentar (GONÇALVES, 2014).

Conforme Marmitt (1993), a reciprocidade encontra força nos artigos 1.694 e 1.696 do Código Civil, porque "o devedor de hoje pode ser o credor de amanhã, quanto ao ônus alimentar" (MARMITT, I993, p.28). Como se pode analisar da leitura da parte final do disposto no artigo I.696, a reciprocidade é extensível aos parentes mais próximos, uns na 
falta dos outros, sendo assim, caso o pai venha a falecer, pode o neto vir a pleitear o pedido de alimentos em face do avô.

Da mesma maneira, de acordo com o princípio citado, poderá o avô requerer alimentos do neto, ou na falta desse, do bisneto, sempre se analisando o pressuposto de necessidade de quem pede os alimentos e a possibilidade econômica de quem é demandado de arcar com esse ônus.

De acordo com Madaleno (2013):

A reciprocidade não significa que duas pessoas devam alimentos entre si, mas tão somente que o devedor de hoje poderá ser o credor e tampouco se confunde com a reciprocidade das obrigações bilaterais derivadas de um contrato sinalagmático, onde ambos são credores e devedores ao mesmo tempo, pois é impossível em uma relação alimentícia, que ao mesmo tempo recaia sobre as mesmas pessoas um dever e um direito de alimentos, pois entra em jogo a situação de necessidade de quem ocupa a posição de credor e a condição de possiblidade daquele que se vê obrigado a prestar os alimentos (MADALENO, 2013, p.888).

Para compreensão deste princípio, deve-se ter em mente que o potencial que o sujeito tem para ser credor na relação obrigacional alimentar, também terá esse mesmo potencial para ser devedor no futuro.

A reciprocidade apenas será invocável respeitando aspectos éticos. O credor só poderá invocá-la em seu favor, uma vez que no passado não deixou de cumprir com suas obrigações em face do devedor que necessitava dos alimentos (DIAS, 20II).

A relativização do princípio da reciprocidade se encontra cada vez mais presente nos entendimentos jurisprudenciais e na Doutrina, uma vez que a reciprocidade alimentar só é invocável quando há ética da parte pedinte, levando em consideração que no passado se não houve assistência ao devedor de alimentos de agora, é descabido requerer dele posteriormente a ajuda que deixou de prover no passado.

\section{I Aplicações analógicas dos artigos 557 e 1814 do código civil e na obrigação alimentar}

Atualmente, na legislação brasileira, verifica-se a ausência de dispositivos que tratam expressamente sobre a relativização do princípio da reciprocidade na obrigação alimentar entre pais e filhos. Nas decisões judiciais os magistrados têm se utilizado analogicamente dos artigos 557 e I.8I4 do Código Civil para justificar a relativização do princípio da reciprocidade em comento, ou então se baseiam na previsão do artigo 92, II do 
Código Penal para embasar a cessação da obrigação alimentar, quando um genitor comete crime contra o descendente.

Os dispositivos trazidos pelo Código Civil, porém, tratam respectivamente da revogação da doação e da exclusão da sucessão, não se tratando sobre revogação da prestação alimentícia, conforme se verifica abaixo nos artigos 557 e r.8I4 do Código Civil de 2002:

Art. 557. Podem ser revogadas por ingratidão as doações:

I - se o donatário atentou contra a vida do doador ou cometeu crime de homicídio doloso contra ele;

II - se cometeu contra ele ofensa física;

III - se o injuriou gravemente ou o caluniou;

IV - se, podendo ministrá-los, recusou ao doador os alimentos de que este necessitava.

Art. I.814. São excluídos da sucessão os herdeiros ou legatários:

I - que houverem sido autores, co-autores ou partícipes de homicídio doloso, ou tentativa deste, contra a pessoa de cuja sucessão se tratar, seu cônjuge, companheiro, ascendente ou descendente;

II - que houverem acusado caluniosamente em juízo o autor da herança ou incorrerem em crime contra a sua honra, ou de seu cônjuge ou companheiro;

III - que, por violência ou meios fraudulentos, inibirem ou obstarem o autor da herança de dispor livremente de seus bens por ato de última vontade. (BRASIL, 2002, s/p)

Diante do exposto nos artigos 557 e I.8I4, verifica-se que não há previsão sobre a cessação da prestação de alimentos, levando os magistrados ao uso da analogia para tratar dos casos concretos em que o atual credor de alimentos está pleiteando pedido de pensão alimentícia em face de seu devedor, sendo que no passado deixou de fornecer os cuidados inerentes do seu dever familiar, e atualmente invoca o princípio da reciprocidade contra aquele (BEZERRA, 2015).

O artigo 92, II do Código Penal preceitua que:

Art. 92 - São também efeitos da condenação:

II - a incapacidade para o exercício do pátrio poder, tutela ou curatela, nos crimes dolosos, sujeitos à pena de reclusão, cometidos contra filho, tutelado ou curatelado. (BRASIL,1940, s/p)

Não obstante o dispositivo tratar sobre os efeitos da condenação penal, lembre-se de que a norma é aplicada analogicamente ao instituto dos alimentos. Ao incorrer, portanto, 
em uma dessas hipóteses, pode o genitor perder seu direito à prestação mantenedora de seu sustento, porque ao ser destituído do poder familiar, deixará de prestar assistência ao menor e assim não poderá invocar o princípio da reciprocidade para fundamentar a obrigação alimentar no futuro.

\subsection{Hipóteses que relativizam o princípio da reciprocidade na prestação de alimentos entre pais e filhos}

Diante do exposto, surge o problema principal sobre a possibilidade de relativização do princípio da reciprocidade na prestação de alimentos.

Tendo como base a jurisprudência, é possível relativizar o princípio da reciprocidade na prestação de alimentos, uma vez que o credor de alimentos que deixou no passado de cumprir com seus deveres afetivos inerentes do poder familiar, terá seu pedido de alimentos indeferido. Nesse sentido já decidiu o Egrégio Tribunal de Santa Catarina ao indeferir o pedido de alimentos pleiteado por um genitor em face do filho. Vejamos:

DIREITO CIVIL - FAMÍLIA - ALIMENTOS - PEDIDO FORMULADO
PELO PAI CONTRA O FILHO MAIOR DE IDADE - IMPROCEDENCIA
DO PEDIDO INICIAL - INCONFORMISMO - NECESSIDADE
DEMONSTRADA - AFASTAMENTO - POSSIBILIDADE FINANCEIRA
DO ALIMENTANTE - INCOMPROVAÇÃO - ALIMENTANTE RECÉM
FORMADO - AUSÊNCIA DE CONDIÇÃO FINANCEIRA - OBRIGAÇÃO
ALIMENTÍCIA VINCULADA AO PRINCÍPIO DA SOLIDARIEDADE -
INADIMPLEMENTO OBRIGACIONAL PATERNO DECORRENTE DO
PODER FAMILIAR - SENTENÇA MANTIDA - RECURSO IMPROVIDO.
O pedido alimentar formulado pelo ascendente ao descendente com fundamento
no art. I. 696 do CC exige demonstração inconcussa da necessidade alimentar e da
capacidade financeira do alimentante de prestar auxílio ao genitor. Em face do
caráter solidário da obrigação alimentar, inacolhe-se pleito formulado por genitor
contra filho maior de idade se este não recebeu por ocasião de sua menoridade os
cuidados paternos inerentes ao pátrio poder a que tinha direito (SANTA
CATARINA, zoI3, $\mathrm{s} / \mathrm{p}$ ).

Nessa hipótese em que ocorre o abandono afetivo, pois o genitor deixou de prover no passado os cuidados inerentes do poder familiar ao seu descendente, restou descaracterizada a reciprocidade da obrigação alimentar, uma vez que o pai não pode exigir do filho aquilo que não veio a fornecer no passado.

Nesse sentido, defende Negrão (2012):

É descabido o pedido de alimentos, com fundamento no dever de solidariedade, pelo genitor que nunca cumpriu os deveres inerentes ao poder familiar, deixando 
de pagar alimentos e prestar aos filhos os cuidados e o afeto de que necessitavam em fase precoce de seu desenvolvimento. (NEGRÃO, 2012, s/p).

Compartilhando do raciocínio supracitado, leciona Dias (2006) acerca da reciprocidade da obrigação alimentar:

A obrigação alimentar é recíproca entre cônjuges, companheiros (CC 1.694) e parentes (CC 1.696$)$. [...] A reciprocidade tem fundamento no dever de solidariedade. Com relação aos alimentos decorrentes do poder familiar, não há falar em reciprocidade ( $\mathrm{CF}$ 229). Porém, no momento em que os filhos atingem a maioridade, cessa o poder familiar e surge, entre pais e filhos, obrigação alimentar recíproca em decorrência do vínculo de parentesco. A reciprocidade é invocável dentro do aspecto ético. Assim, o pai que deixou de cumprir com os deveres inerentes ao poder familiar não pode invocar a reciprocidade da obrigação alimentar para pleitear alimentos dos filhos quando atingirem eles a maioridade (DIAS, 2006, p. 408-409).

O mesmo incorreria para o descendente que viesse a deixar de prestar assistência ao genitor com dificuldades e, futuramente, ocorrendo a inversão deste papeis, o filho viesse a passar dificuldades financeiras em virtude de invalidez e pleiteasse pedido de pensão alimentícia ao pai, tendo também esse pedido indeferido por não ter auxiliado no passado.

Sem desmerecer mais essa conquista legislativa no nosso ordenamento, a relativização do princípio da reciprocidade na obrigação alimentar entre pais e filhos, é um meio de a justiça analisar que nem sempre poderá haver a obrigação de uma pessoa a prestar alimentos a outra, mesmo que quem necessite seja seu filho ou seu pai.

Assim, em razão de inúmeras transformações e evoluções sofridas pela entidade familiar no decorrer dos tempos, de modo a entristecer, o que se vê nos dias de hoje é um verdadeiro e crescente retrocesso mental do ser humano. É um paradoxo que infelizmente se constata.

Amor, carinho, solidariedade e outros mais sentimentos inerentes ao ser humano que não eram valorizados nas eras primitivas de existência, estão, no ápice da modernidade, a se esfarelarem pouco a pouco. Pais e filhos se esquecem do liame sanguíneo e do afeto que os rodeiam e por muitas vezes se tornam inimigos. A necessidade, miserabilidade não é mais motivo de ressentimento para muitos na atualidade, inclusive para aqueles que deveriam se importar indiscutivelmente com o bem estar do outro (DIAS, 20II). 
Outra corrente doutrinária defende o contrário, que não é possível relativizar o princípio da reciprocidade na prestação de alimentos, uma vez que os alimentos possuem caráter absoluto.

Ainda de acordo com Quaranta e Oliveira (2013), seria injusto "que o ascendente, quanto atingisse uma idade avançada e não tivesse condições de prover o próprio sustento, não pudesse contar com o auxílio material dos descendentes" (QUARANTA; OLIVEIRA, 2013, s/p).

Em conformidade ao que ora se aduz, decidiu o Tribunal de Justiça do Rio de Janeiro em recurso de apelação sobre o tema:

APELAÇÃO CÍVEL. AÇÃO DE ALIMENTOS PROPOSTA POR MÃE EM
FACE DOS FILHOS. DEVER DOS FILHOS MAIORES EM AMPARAR OS
PAIS NA VELHICE. ARTIGO 229 DA CONSTITUIÇÃO DA REPÚBLICA.
RECIPROCIDADE DE ALIMENTOS PREVISTA NO ARTIGO I696 DO
CÓDIGO CIVIL. COMPROVADA DEVIDAMENTE A NECESSIDADE
DOS ALIMENTOS POSTULADOS. ALIMENTOS DEFINITIVOS
FIXADOS EM PERCENTUAL QUE ATENDE À POSSIBILIDADE
COMPROVADA DOS FILHOS E QUE ESTÁ EM CONSONANCIA COM
O TRINÔMIO NECESSIDADE-POSSIBILIDADE-RAZOABILIDADE.
ARTIGO I694 DO CÓDIGO CIVIL. CORRETA A SENTENÇA. NÃO
PROVIMENTO DO RECURSO DE APELAÇÃO (RIO DE JANEIRO, 2OI4,
s/p).

Madaleno (2013), no mesmo sentido, garante:

A solidariedade familiar entre pais e filhos é ilimitada e vai ao extremo de exigir a venda de bens para cumprimento da obrigação filiada ao princípio constitucional do direito à vida, dentro da dignidade da pessoa humana (arts. $\mathrm{I}^{\mathrm{o}} \mathrm{e}$ $5^{\circ}$, da CF), [...] quando se admite ser ilimitada a obrigação dos pais de prestar alimentos ou sustentar seus filhos, assim como seriam ilimitados e imensuráveis os esforços e sacrifícios paternos, em prol da prole, no íntegro dever diário da sociedade conjugal, sobrepondo-se aos seus interesses pessoais, quando em confronto com as necessidades dos descendentes menores, ou incapazes de por si buscarem seu efetivo sustento (MADALENO, 2013, s/p).

O autor defende que a solidariedade familiar é ilimitada e que assim os familiares devem poder contar uns com os outros na dificuldade, sendo que tais esforços solidários devem ser imensuráveis, ao ponto de chegar à venda de imóveis e demais bens para prover as necessidades daqueles que se encontram com dificuldades, se sobrepondo aos interesses pessoais do devedor de alimentos (MADALENO, 2013).

Outro autor que segue a mesma linha de pensamento é Gonçalves (2014), preceituando que 
O dever de prestar alimentos (art. I.694) a parentes, cônjuge ou companheiro, que pode ser transmitido aos herdeiros no limite dos bens que receberem (art. I.70o), além de ser irrenunciável (art. 1.707), decorre da imposição de solidariedade entre pessoas ligadas por vínculo familiar. (GONÇALVES, 2014, p.64)

O autor civilista defende que o dever de prestar alimentos é decorrente da imposição solidaria entre as pessoas ligadas por um laço familiar, devendo se amparar entre elas.

Contrário a primeira corrente doutrinaria que defende que a afetividade teria relação com o afeto entre os membros da família, Gonçalves (2014) entende que nada disso teria relação, uma vez que independente da relação entre pai e filho, ou qualquer outro parente da família, o dever da prestar alimentos é recíproco e preceitua que

\begin{abstract}
A afetividade, como princípio jurídico, não se confunde com o afeto, como fato psicológico ou anímico, porquanto pode ser presumida quando este faltar na realidade das relações; assim, a afetividade é dever imposto aos pais em relação aos filhos e destes em relação àqueles, ainda que haja desamor ou desafeição entre eles. O princípio jurídico da afetividade entre pais e filhos apenas deixa de incidir com o falecimento de um dos sujeitos (GONÇALVES, 2014, p.7I).
\end{abstract}

Compartilhando do mesmo pensamento, Miranda (2013) afirma que

A obrigação à prestação de alimentos é recíproco no direito brasileiro, uma vez que se estende em toda a linha reta entre ascendente e descendentes, e na colateral entre os irmãos, que são parentes recíprocos por sua natureza. E é razoável que assim seja. Se o pai, o avô, o bisavô, tem o dever de sustentar aquele a quem deram a vida, injusto seria o filho, neto ou bisneto, abastado, não fosse obrigado a alimentar o seu ascendente incapaz de manter-se (MIRANDA, 2013, p.522).

Dessa forma percebe-se que o autor também defende a mesma ótica da injustiça quanto ao ascendente não receber pensão alimentícia de seu descendente, sendo ele obrigado a cooperar com aquele pelo fato da consanguinidade.

\title{
CONCLUSÃO
}

Postas as situações e hipóteses, pode-se analisar as duas vertentes doutrinarias e as jurisprudências de possibilidades da relativização do princípio da reciprocidade na prestação de alimentos. Uma delas demonstrou a possibilidade, uma vez que a Egrégia Corte já decidiu a respeito, entendendo que em casos em que o pai deixou de prestar com seus deveres afetivos com o filho inerentes ao pátrio poder e futuramente vem postular em face de seu descendente em momento de dificuldade o pedido de pensão alimentícia, terá seu requerimento indeferido, pois a reciprocidade não pode ser invocada quando não foi 
exercitada no passado, sendo assim possível relativizar o princípio e desobrigar a parte requerida da prestação de alimentos.

Da mesma forma Dias, Negrão e outros autores não veem a reciprocidade como um princípio absoluto, de modo que as alegações dos vínculos de consanguinidade não mais seriam suficientes para que se possa obrigar um ente familiar a prestar alimentos a outro, sendo possível se isentar da obrigação nos casos de abandono afetivo.

Outra corrente doutrinária analisada no presente trabalho entende que a obrigação de prestar alimentos é um direito recíproco no direito brasileiro, defendendo que seria injusto que os familiares não possam contar uns com os outros nos momentos de necessidade, uma vez que isso pode ferir o princípio da dignidade da pessoa humana, não podendo alguém que se encontra em dificuldades ficar em desamparo e não poder contar com o auxílio daqueles por quem deram a vida. Defendem, ainda, que nos casos em que o abandono afetivo poderia afastar a obrigação alimentar, o afeto não se confundiria com a afetividade e mesmo que haja desafeição entre pai e filho ou qualquer outro ente familiar, a falta de afeto não seria causa de excludente da obrigação familiar, sendo injusto e contrário à jurisdição deixar de prestar auxílio aquele que está passando por uma enfermidade, está desempregado, inválido ou até mesmo idoso e não possui condições de prover com o próprio trabalho a sua subsistência.

Diante dos entendimentos, das jurisprudências e dos Doutrinários analisados no presente estudo, entende-se que seria possível a relativização do princípio da reciprocidade na prestação de alimentos, quando no passado o credor de agora deixou de cumprir com suas funções assistenciais de que tinha dever enquanto detinha o poder familiar. Posteriormente, ao solicitar alimentos daquele, nesse caso será descabido qualquer direito sobre a fundamentação do princípio da reciprocidade, uma vez que a reciprocidade só pode ser invocada quando houve de fato assistência no passado para quem está sendo requerido agora.

\section{REFERÊNCIAS}

BRASIL. Código Penal de 1940. Promulgado em 7 de dezembro de 1940. Disponível em: 〈http://www.planalto.gov.br/ccivil_03/decreto-lei/Del2848.htm>Acesso em: Io out. 2017. 
- Código Civil de 2002. Promulgado em to de janeiro de 2002. Disponível em: 〈http://www.planalto.gov.br/ccivil_03/leis/2002/Lio406.htm〉 Acesso em: Io out. 2017.

Constituição Federal de 1988. Promulgada em 5 de outubro de 1988. Disponível em: 〈http://www2.planalto.gov.br/> Acesso em: Io out. 2017.

- Estatuto do Idoso. Promulgado em I de outubro de 2003. Disponível em: 〈http://www.planalto.gov.br/ccivil_03/leis/2003/Lio.74I.htm> Acesso em: Io out. 2017.

BEZERRA, Denilson Ribeiro. O dever de prestar alimentos entre pais e filhos e as hipóteses que relativizam o Princípio da Reciprocidade. 2015. Disponível em: $\langle$ https://denilsonbezerra.jusbrasil.com.br/artigos/246328091/o-dever-de-prestar-

alimentos-entre-pais-e-filhos-e-as-hipoteses-que-relativizam-o-principio-da-reciprocidade> Acesso em: is out 2017.

CAHALI, Yussef Said. Separações Judiciais e Divórcio. São Paulo: RT, 2011.

CALDERÓN, Ricardo Lucas. Princípio da afetividade no direito de família. Rio de Janeiro: Renovar, 2013. Disponível em: $\langle$ http://www.egov.ufsc.br/portal/sites/default/files/principio_da_afetividade_no_direito_ de_familia.pdf $>$ Acesso em: 13 out. 2017.

CARVAlHO, Dimas Messias de. Direito de família. Belo Horizonte: Del Rey, 2009.

DIAS, Maria Berenice. Manual de Direito das Famílias. São Paulo: RT, 201 .

DINIZ, Maria Helena. Curso de direito civil brasileiro. São Paulo: Saraiva, 2012.

FARIAS, Cristiano Chaves de; ROSENVALD, Nelson. Direito das Famílias. Rio de Janeiro: Lumen Juris, 2012.

GONÇALVES, Carlos Roberto. Direito civil brasileiro, vol. 6: direito de família. São Paulo: Saraiva, 2014.

MADALENO, Rolf. Curso de Direito de Família. Rio de Janeiro: Forense, 2013.

MARMITT, Arnaldo. Pensão alimentícia. Rio de Janeiro: Aide, 1993.

MIRANDA, Pontes de. Direito Civil Brasileiro. São Paulo: Saraiva, 2013.

NEGRÃO, Theotonio. Código Civil e legislação em vigor. Saraiva: São Paulo, 2012. PEREIRA, Rodrigo da Cunha. Alimentos no código civil. São Paulo: Saraiva, 1997. 
QUARANTA, Roberta Madeira; OLIVEIRA, Érica Siqueira Nobre de. A obrigação de prestar alimentos entre pais e filhos: o dever de reciprocidade. 2013. Disponível em: 〈https://jus.com.br/artigos/25429/a-obrigacao-de-prestar-alimentos-entre-pais-e-filhos〉 Acesso em: 30 out. 2014 .

RIO DE JANEIRO, Tribunal de Justiça. APELAÇÃO CÍVEL. AÇÃO DE PEDIDO DE ALIMENTOS. APL - ooroo528820128190209. Estado do Rio de Janeiro. Rel.: Eduardo de Azevedo Paiva, Décima Nona Câmara Cível. Julgamento: 28 jan 2014. Disponível em: 〈https://tj-rj.jusbrasil.com.br/jurisprudencia/Ir6641954/apelacao-apl-I00528820128190209-rjooroo52-8820128190209> Acesso em: 14 out 2017.

RODRIGUES, Silvio. Direito Civil: direito de família. São Paulo: Saraiva, 2004.

SANTA CATARINA, Tribunal de Justiça. APELAÇÃO CÍVEL.AÇÃO DE PEDIDO DE ALIMENTOS. AC - 1052239-5, Apelante: Renato de Camargo. Apelado: Ney Rolim de Alencar Fiho. Estado de Santa Catarina. Rel.: Monteiro Rocha, Segunda Câmara de Direito Civil Julgado. Julgamento 9 out 2013. Disponível em: $\langle$ https://tjsc.jusbrasil.com.br/jurisprudencia/24269712/apelacao-civel-ac-20130350338-sc-2013035033-8acordao-tjsc> Acesso em: 14 out 2017.

VENOSA, Sílvio de Salvo. Direito Civil: Direito de Família. São Paulo: Atlas, 2003. 